\title{
The Institution of Masking, Wall and Body Painting in Traditional Igbo Society
}

\author{
Ndubuisi Chinyere
}

\author{
PhD., Department of Fine Art, Yaba College of Technology, Lagos, Nigeria \\ chinyere.ndubuisi@yabatech.edu.ng
}

\begin{abstract}
The art of masking and masquerading formed a known institution in Igbo society, which constitutes only males members. The institution was religious in nature thus, its influence in the maintenance of peace and order in the community. In addition, the institution was associated with law enforcement; whereby the masquerade could walk up to an individual and expose his/her secrete ills even while performing. These acts often serve as corrective measures, as nobody wants to be exposed publicly; hence its effectiveness in ensuring that traditional norms and values were kept. On the other hand, the art of wall and body painting which is known as Uli traditional painting was practised by only women in Igbo society. Apart from the mere purpose of decorating walls and female bodies for traditional ceremonies, it was also used for training of the girl child, who looks forward to womanhood in order to be part of the decorative team. These two institutions flourished during the pre-colonial era and are both gradually going into extinction. It is against this background that this paper proposes an examination of culture and leadership in pre-colonial Igbo society. It intends to show that there is a strong tie between art and leadership during the pre-colonial era, as well as $x$-ray the effect of civilization on traditional art institutions.
\end{abstract}

Keywords- Masking, Masquerading, Norms, Values, Uli, Institution.

\section{INTRODUCTION}

The Igbos constitute one of the three major ethnic groups in Nigeria. They fully occupy the following states: Anambra, Imo, Abia, Enugu and Ebonyi states and some parts of Delta and Rivers states of Nigeria. According to (Ifemesia 1979, 2)"these area includes the forest belt area between the Cross River and Benin, west of the Niger, and between the Igala to the North and the Niger Delta city-states to the south".

Generally, masks are artificial faces worn over the real face for disguise during masquerade performance. In Igbo land, mask and masquerades are not mere objects of disguise and performance, rather they are perceived as higher being and they are generally believed to be the spirit which springs from the soil,hence the name 'Nmonwu' which translates 'spirit' in the English language. Masking in Igbo land represents all types of being, which includes supernatural and human beings, both male and female, and all types of creatures from the animal kingdom. Some masks fantastically combine elements from different categories and may even serve as a reminder of the ancestors and ancient deities of the society. Most traditional Igbo masks were carved from wood; and in carving the mask, the artist finely texturize the surface of some masks with details in some other cases, he could apply minimum details. Masks are created to express a certain feeling and impression. (Lechuga and Sayer 1994, 11) assert, "Mask may evoke ambition, violence, virtue, wisdom, simplicity, or plain stupidity".

There are different classes of masquerades, and their class depends on their performance. Some masquerades warrior-like expertise, mystical powers, youthfulness, and old age, each masquerade performs specialized skills such as dancing, acrobatics, and other ritual manifestations, while some perform multiple skills. Mask can inspire sympathy; create fear, particularly when they are designed for corrective purposes.

Masquerade seldom perform alone, it is usually a teamwork that constitutes of instrument players, vocalists, dancers, advisers, and the masquerade itself. The masquerade attire comprises of fabric, rafters, and a wooden mask that is worn over the face. During a performance, there could be competition among different types of masquerade in the village square. The essence is to showcase their different powers to human beings as the claim to be spirited as well as to determine the most powerful one. However, every occasion determines the type of masquerade performance.

The masquerade performance is central to most Igbo ceremonies, thus it incorporates other cultures such as Uli wall and body painting. Uli body painting was an Igbo women's art. The art in most cases was the collections of the artist in charge; that was painted on women during major occasions in Igbo land such as marriage. For the Igbo's, Uli body painting was a form of visual communication whereby a woman's skin was used as an 
artist's ground to express artistic symbols and relevant motifs.

Aside from the body, the women also express themselves on the wall of the family compound or public buildings such as the village shrine. The symbols used by the women often represented things of physical importance that were aesthetically pleasing, since the main purpose of Uli was purely decorative, and training of the girl child. (Smith 2010, 3-4) says, "Uli was for aesthetic appeal, and was intended to beautify the female body or clay/mud walls, as beauty was equated with morality in Igbo culture". Young girls learned the art of body painting by observing their mothers, grandmothers, or other women in the community. Smith states, "Once a woman was proficient at uli, her skill was employed in events such as title taking, marriages, seasonal celebrations, and memorial services for the dead". Because of the recognition that was accorded to proficient Uli designer, the young learners pay apt attention so that they could grow to such statues and attract similar recognition.

\section{THE INSTITUTION OF MASKING IN TRADITIONAL IGBO SOCIETY}

Masking is an institution in Igbo land that is charged with the power of justice and it was a men's affair and strictly by initiation. The role of Mask and masquerading in traditional Igbo setting cannot be overemphasised. This can be seen in the coronations of kings and chiefs, agegrades, priest of deities, marriage, burials ceremonies among others. in addition, the play important role in the issue of governance, social control and maintenance of peace and order. The people believe so much in them in accomplishing all the above-mentioned roles and even more, because they were seen as spirits in the physical realm, the reason why (Onyeneke 1987, 10) refers to them as "the Dead Among the Living". People accord a lot of respect for them. (Ogbonna 1984, 12) opines, "masked figures provide a mechanism through which the probability of sustained divisive conflict is decreased by converting secular actions of rule application into sacred, supra social actions".

Traditional in Igbo land, there were sacred institutions with significant religious roles to ensure that community values and ideals were kept. The masquerade society was among these institutions; that suggest important religious beliefs, they were believed to also have supernatural power and authority, as well as served important role in ensuring that values and ideas were inculcated in people to promote harmonious living in the society. The masquerades possess spiritual and mystical powers and in most cases, they were regarded as ancestors or divinity. According to (Ejizu 2011, 4) "Masquerades are a highly symbolic public institution and performance among traditional African groups ... they evoke a wide variety of significant ideas and values concerning the social, occupational, political and religious aspects of the life of traditional peoples"

Among other roles of masquerades in Igbo land, were to identify and represent respectively social and religious groups. They were also closely associated with political, social and occupational quests of the people. (Nwankwo 2015, 84) observes, "Primarily, masquerades are thought of by Africans as powerful sacred symbols. They represent lineage ancestors and serve as the visible expression of the spiritual force and authority believed to validate the basic beliefs and values of society". In Igbo traditional society, it was believed that the masquerade institution is responsible for the eradication of ills, an institution that binds people together. They also reinforce social modes of conduct and symbolize the spiritual authority that eradicates social evils. (Nwala 1975, 88) also observed thus,

Masked dancers purporting to represent the spirit cult were used whenever there was difficulty in enforcing law and order in Igbo communities. This is another indication that masquerades were probably more efficient than the ordinary human elements in rule application. As social control agents, masquerades were unchallengeable. They intervened in land disputes, summoned people for communal work and collected levies from deviants. They were dreaded and thought to have the power of life and death.

The role of masquerades in the traditional society made it possible for individuals to comply with the law and order of the society as they were afraid of attracting the wrath of the masquerade. In Ohuhu community of Umuahia, in Abia state, some notable masquerades were, Atu, Odogwu Anyamiri, Ekpe, among others. These masquerades performed different tasks, ranging from the application of rules, entertainment to social control. These masquerades enforced the societal rules on people that violated such rules, as such they were handy in day to day governance, prevention and reformation of deviants in traditional Igbo society. (Ogbonna 1984, 12) observes,

The traditional man was very concerned of his good name and therefore most willing to adjust his anti-social behaviour along accepted lines rather than have his name ridiculed in the dead night by voices representing those of his ancestors whom he longed to join in subsequent life...to disobey the 
masquerade is to be at crossroad with both the living and the dead which no man attempted to be.

Depending on the society that presents the masquerade, it was forbidden for women and children to see some masquerades. For example, the masquerades of the 'Okonko' secret society group in Ohuhu Abia Stae performs only at night, hence women, children and even men who were not members of the society were forbidden to see such masquerades.

(Ejizu 2011, 34) reports, "They walk at night, and early in the morning, ...The primary obligation of this masquerade is to break into the house of anybody that defaults the laws of the land and destroy whatever it can lay its hands on and urges the person to pay to the society whatever it is demanding".

Masking was also an institution used during initiation of boys into manhood. This particular occasion features strong masquerades that showcase the male strength and the ultimate physical strength they possess. Hence during the manhood celebrating, masquerades such as Ijele were showcased, because Ijele was the biggest and strongest masquerade of the Igbos. In Igbo society, the masquerade is one of the means through which the physically strongest was identified.

The institution of masking in Igbo land was also charged with the task of uniting the village that showcases it and its neighbourhood. People look forward to occasion such as the new yam festivals for masquerade performance that will take them from one village to the other. This is because most Igbo villages celebrate the new yam festivals and other traditional festivals on the market days, therefore setting different days for different villages. (Nwankwo 2015, 13) asserts, "Form of Sports for Uniting Neighboring Villages Masquerade is another means Igbo societies integrate with each other. Masquerade in those days is like today's intercontinental football and Olympic game". Apart from the performance that people watch as a means of entertainment, villages organised a competition among masquerades. This was a very big event as people from different villages gathers in a particular village square for the contest. Different masquerades were showcased at such contest, where the masquerades tousle their power and a winner emerges at the end of the context as the strongest masquerade of the season.

\section{ULI WALL AND BODY DECORATION}

An important occasion in the life of Igbos such as, birth, marriage, and burial attracts beautification of the environment, public and private buildings as well as the people that participate in the occasion. Majorly, an average Igbo man pays particular attention to the general appearance of his wife, thus the need for the woman to present herself gorgeously on such occasions. For this reason, uli body decoration comes to play on such occasions. (Smith 2010, 98) supports the above thus, "To fit an occasion, Igbo women decorated their bodies with uli. Uli transfigured the body, enhanced an individual's appearance, and drew attention to a woman's status"

Apart from the three ceremonies mentioned above, uli was also used during title taking and age grading. Title taking and age grading in Igbo land cuts across both male and female, however, the titles were not given to everyone; rather it was given to only those that prove themselves worthy of the title. For Igbo women to qualify for their desired titles and wears Uli decorations there was the need for good behaviour and extra work. (Smith 2010,101) asserts "Therefore, a titled woman was distinguished from other women and highly respected, and those who showed leadership potential could often hold public office. More importantly, title taking safeguarded women against destitution and guaranteed them some sense of security".

In addition to all other roles uli played in the life of the Igbo women, it helped in the training of the girl child into a responsible woman. It is the desire of every Igbo girl to marry and every Igbo parent to give out her daughter to marry. Marriage in Igbo land is the pride of every woman, thus the saying 'Nma nwanyi bu di ya'; which translates: the beauty of a woman is her husband. (Nwankwo 2015. 112) observers, " During this period of time, a young woman was instructed on her soon to be roles as wife and later mother. These responsibilities required a clear understanding of traditions and customs, as well as domestic responsibilities. Most importantly good manners, since in Igbo culture good manners constitute beauty". To this reason, every girl child puts up the best behaviour to get to the stage where she could get married and beautify with Uli on her marriage. Before the marriage rites were performed, the woman was kept in an enclosed room for a minimum of three months. The enclosure is popularly known as a fattening room. Adams (2002, 28) notes, "...when the girls emerged from seclusion, they were presented to the community at the height of their beauty. For the occasion, their bodies were covered in sumptuous garments of black line body art and their hair was meticulously styled". At this point in the life of every girl child in Igbo land, it was assumed that she had qualified the character test and accepted into womanhood. The uli was heavily drawn on the body of such individual to celebrate her during such celebrations; the wealthy ones amongst them also decorated the walls of their houses with uli designs. Uli played a vital role in the upbringing of a girl child in Igbo land because every 
girl puts up good behaviour and conduct, to enable her to wear the design as a bride.

Aside marriage, other occasions in the life of an Igbo woman that attracts Uli decoration was the naming ceremony. Traditionally, Igbos names a child after three months of delivery. During the naming ceremony, the mother was to enable the child and the mother to be strong for the ceremony. Also on the village market day, the mother was expected to present the child to the other women in the market, thus another Uli decoration is worn on her. (Smith 2010, 117-118) asserts "More importantly, it was customary for a mother to take her child to market for the village/community women to admire. During the pleasant visit, women complimented and praised the new mother for giving birth to a healthy and beautiful child. It was also a day that gifts were presented to both the mother and the child".

It has been observed that burial was one of the celebrations in Igbo land that attracts Uli decorations. Among the Igbo, burial could mirror a person's background, title, gender, and relationship with his family and the society at large. One of the criteria for an elaborate burial was the age of the deceased, thus, it is the wish of everyone to live long so as to attract celebration at death. Also, for a deceased to be celebrated, it is expected that he/she must have successful children, and must have lived a good life and be a prominent member of society, when all the above criteria were meet, it was assumed that the person was not dead, rather he has gone to join his ancestors, thus the person was celebrated. For such a deceased, there was usually a considerable wailing and drumming, to inform people that the ancestors have received another worthy person. Therefore, burial was important occasionsthat attracted beautification of the environment, public and private buildings as well as the individuals that participated in the occasion. For this reason, uli wall and body decoration come to play on such occasions. (Smith 2010, 122-123) supports the above thus, "To fit an occasion, Igbo women decorated their bodies with uli. Uli transfigured the body, enhanced an individual's appearance, and drew attention to a woman's status"

Apart from the three ceremonies mentioned earlier, uli was also used during title taking and age grading. Title taking and age grading in Igbo land cuts across both male and female, however, the titles were not given to everyone; rather it was given to only those that prove themselves worthy of the title. For Igbo women to qualify for their desired titles and uli decorations, they worked extra hard, as such the institution of uli plays important role in their lives and behaviours. (Smith 2010, 125) says, "Therefore, a titled woman was distinguished from other women and highly respected, and those who showed leadership potential could often hold public office. More importantly, title taking safeguarded women against destitution and guaranteed them some sense of security".

\section{THE ARTIST AND THE INSTITUTIONS OF MASKING AND ULI}

The artist plays important role in the decoration of either the body or the wall. They choose the pattern that is most appropriate for the occasion as well as the pigment that will stand the time of the occasion.

special patterns were chosen by the women that made a personal statement about the family members as holding position or titles. On the other hand, the women would often rely on the uli artist to select and paint motifs that best fit the occasion.

Wall and bodies of fellow women in traditional Igbo society stand as the ground for uli painting and drawing, thereby turning the body or wall on which it is painted into an artwork.

The primary source of uli dye were trees and shrubs that produce seed pods which flower and bear fruits at different times, this makes it possible to have the dye substance all year round. (Obuh 1984, 38) notes, "the liquid dye is from the Rothmania hispida (uli okorobian) or Rothmania Whitfield (uli oba or uli nkpo), along with a variety of other small trees and shrubs found in most parts of the Igbo speaking regions". The women grind the pond/seed and extract the liquid that is used as a dye on the body. In some cases, the women added charcoal to the dye to strengthen the dye and its effects. Just as the painter primes the canvas for use, Igbo women prepares the body on which uli was applied with powder from camwood as observed by (Smith 2010, 111), "First, she used various razors and implements to shave off unwanted body hair prior to rubbing the body with powdered camwood (ufie). Ufie, which is dark red/purple in colour, comes from the heartwood of a mature abosi or camwood tree (Baphia nitida or Baphia pubescens)... The ufie (camwood powder), used as a primer, made the skin cool and smooth and prevented perspiration that could easily cause smudges as the dye was painted on the body".

The priming of the body makes the drawing of uli design easy for the women. They easily draw lines from nature and traditional motifs on the body. Among the tools used to draw the uli designs on the body was a blunt knife (mmanwauli), other tools are, palm fronds, feathers, stems from various plants, or stamping devices made from plants or vegetables. (Obuh 1984, 42), asserts, "In the Nri-Awka area, small metal combs with between five to ten teeth were used for tracing a series of parallel lines on the body. ... In Uzuakoli, Abia State, women often used their thumbnail or nail of the forefinger to make patterns 
or to define other markings. Due to the fluidity of the dye, accidental drips may occur.

Unlike the uli body painting that is between the artist and the individual that requested for it, uli wall decoration was mostly a contract between the artist and the community as most of the building that requires decoration were public buildings. The process of preparing the wall for painting is similar to that of the body as the artists also prime the wall to get it ready for painting. The wall decoration requires more than one artist because it is timeconsuming.

The murals are created during the dry season; as the rains could wash off the design if done during the rainy season because the artists do not add any form of binder to the paint. On this (Adams 1997, 81) notes, "Therefore, it is essential that the surface of a wall be properly repaired and resurfaced before painting can begin".

Just as colour is applied to the body painting by the women, they also have specific colours for painting clay/mud walls, which were shades of red, brown, yellow ochre, and of course, black and white.

Charcoal according to (Obuh 1984, 118) "is said to be quite permanent on walls, retaining its colour for several years, and often large sections of walls were painted black to be further decorated with red, yellow, or white motifs. Another prominent colour used by the women on the wall is white chalk, which is soaked in water and turn to a fine paste. Other colours are yellow, green which were gotten from plants.

Uli symbols, whether on the body or surface of walls, are known by a variety of names, depending on the region in which they are used. (Ikwuemesi 2005, 6) concedes that, "designs used by women do vary from region to region, and although the meaning of what the uli artist draws depends on her personal interpretation, much depends on the iconographical codes of the village, since meanings and interpretations commonly vary from area to area".

\section{CONCLUSION}

Masquerades among the Igbos are far more than objects of disguise as they are seen presently because they were spirits of the ancestors, evoked by the priests during important occasions, crisis or uncertainties to intervene in the affairs of men and uphold law and order in the community. They were seen and known to have powers of life and death, as such those that have committed evil in the society were summoned before the masquerades for judgement and possible punishments. Thus the masquerade plays a vital role in societal control as it is believed that the spirit can influence the community if things are not going well.

On the other hand, the uli drawing and painting which were drawn by women on fellow women an also on the wall of community buildings also plays important role in the upbringing of the girl child. This is because the women often accompany the painting with songs about parenting and motherhood. However, the common ground between the institution of masking and uli in the Igbo land is that they were both used in the maintenance of law and order as well as upholding the community values. These two institutions were also sustained by the artists because, during the pre-colonial era, art played a major role in bringing down the spirits to live among the people in form of masquerade, and preparing women and the entire community for major festivals with uli decorations.

\section{REFERENCES}

[1] Ifemesia Chieka, Traditional Humane Living Among the Igbo: An Historical Perspective.(Enugu: Fourth Dimension Pub. Co. Ltd. 1979), 2.

[2] Ruth Lechuga and Chloe Sayer, Mask Art of Mexico. London. (Thames and Hudson. 1994), 11.

[3] Smith Sandra,Uli: "Metamorphosis of a Tradition into Contemporary Aesthetics" (master's thesis 2010), 3-4, 98, 101, 117-118, 122-123, 125, 111,

[4] https://etd.ohiolink.edu/!etd.send file?accession=ke nt1267478083\&d isposition=inline.

[5] Onyeneke Augustine, "Dead among the Living: Masquerade in Igbo society". This Day, December 23,1987.

[6] Ejizu, Christopher, "Ofo: Igbo Ritual Symbol,”Journal of Missiology 4, N0. 3(2011), 34

[7] Ignatius Nwankwo, "Governance and Associated Social Roles of Masquerades among The Igbo of Southeast Nigeria in an Era of Globalization: A Critical Appraisal," MgbakoigbaJournal of African Studies, Volume 4, (2015): 84, 13, 112

[8] Nwala Thomas, Igbo Philosophy, (Lagos, Literame Pub. Ltd.1975), 88.

[9] Ogbonna Nnanna,Mmonwu: A Dramatic Tradition of the Igbo, (University Press 1984), 12.

[10] Adams Sarah,Hand to Hand: Uli Body and Wall Painting and Artistic Identity in South-eastern Nigeria.(PhD dissertation 2002), 28, 81. https://www.getty.edu/conservation/publications_res ources/pdf_publications/pdf/decorated_surfaces_vl. $p d f$.

[11] Obuh Stanley, The theatrical use of masks in Igbo Areas of Nigeria. (University Press 1984), 38, 109, 42,118 ,

[12] Ikwuemesi, Kriz, The Rediscovery of Tradition: Uli and the Politics of Culture. (Lagos, Pendulum Art Gallery2005), 6.

[13] Adams Sarah,Hand to Hand: Uli Body and Wall Painting and Artistic Identity in South-eastern Nigeria.(PhD dissertation 2002), 28. 
https://www.getty.edu/conservation/publications_res ources/pdf_publications/pdf/decorated_surfaces_vl. $p d f$.

[14] Chieka Ifemesia. Traditional Humane Living Among the Igbo: An Historical Perspective. Enugu: Fourth Dimension Pub. Co. Ltd. 1979.

[15] Ejizu, Christopher, "Ofo: Igbo Ritual Symbol,"Journal of Missiology 4, N0. 3(2011).

[16] Kriz Ikwemesi, The Rediscovery of Tradition: Uli and the Politics of Culture. (Lagos, Pendulum Art Gallery2005), 6.

[17] Lechuga Ruth and Sayer Chole, Mask Art of Mexico. London. Thames and Hudson. 1994.

[18] Nnanna Ogbonna,Mmonwu: A Dramatic Tradition of the Igbo, (University Press 1984).

[19] Nwankwo Ignatius, "Governance and Associated Social Roles of Masquerades among The Igbo of Southeast Nigeria in an Era of Globalization: A Critical Appraisal," MgbakoigbaJournal of African Studies, Volume 4, (2015): 84.

[20] OnyenekeAugustine, "Dead among the Living: Masquerade in Igbo society". This Day, December 23,1987.

[21] Sandra Smith,Uli: "Metamorphosis of a Tradition into Contemporary Aesthetics". master's thesis 2010.

https://etd.ohiolink.edu/!etd.send file?accession=ke nt1267478083\&d isposition=inline.

[22] Stanley Obuh, The theatrical use of masks in Igbo Areas of Nigeria. (University Press 1984).

[23] Thomas Nwala, Igbo Philosophy, ( Literame Pub. Ltd.1975). 